\title{
セミアクティブェアサンプリング/熱脱着分析を用いた 環境残留性有機污染物質の網羅的モニタリング手法の開発
}

\author{
家田 曜世*11, 高澤 嘉一 $^{1}$, 橋本 俊次 $^{1}$
}

\section{1 緒言}

近年, 法の整備や技術革新が進み，環境に放出される化 学物質による目立った問題は激減している。 その一方で, 化学物質などを取り扱う施設の事故は増加しているように も見える ${ }^{1)}$. 加えて, 自然災害や地震, それらに伴う火災 や施設の倒壊等による化学物質の漏洩事故はたびたび起き ている，すなわち，災害事故に対する危機管理と適切な対 応, その後の環境修復と監視のための体系的な仕組みづく りは，今後の強勒な社会の実現のためには極めて重要であ る.

災害・事故で発生した火災や化学物質の漏洩による周辺 環境の污染の程度と範囲の把握, その後の環境回復の状況 を中長期にわたって監視することは, 住民の安全で安心な 生活を保証するためにも不可欠である．特に居住環境の空 気は, 人が直接吸い込むことから, 健康配虑の面でも重要 な監視媒体である。しかしながら, 半揮発性で残留性もあ る化学物質の測定において, 大気の捕集に一般的に用いら れるハイボリウムエアサンプラー（HVAS）のようなアク ティブエアサンプラーは, 設置場所や外部電源の確保が課 題となるうえに, 台数を確保することも困難である。一方 で, 個人昹露計測や長期観測に用いられるパッシブエアサ ンプラー（PAS）は，接触した空気量（通気量）を知るこ とができず, 大気中濃度換算や定量的な議論が難しい。

そこで著者らは, 災害・事故後の残留物質の中長期的な 監視や大気経由での曝露監視にも対応した効率的・網羅 的・低コストで, 面的・空間的配置も可能とする大気中化 学物質のサンプリング法を開発することを目的とし，簡易 なファンにより通気する構造のセミアクティブエアサンプ ラー（SAAS）を用いたサンプリング手法の開発を行ってき た223). SAAS とは, 気流(乱流)を与え, 拡散体への安定 した捕集を行うためのサンプルホルダーを用いるものであ る. SAAS は, PAS と同様に気一固分配及び分子拡散を利用 し化学物質を捕集するが, PAS とは異なり通気量が記録で

\footnotetext{
* E-mail : ieda.teruyo@nies.go.jp

${ }^{1}$ 国立研究開発法人国立環境研究所環境リスク・健康領域基盤計 測センター：305-8506 茨城県つくば市小野川 16-2
}

きるため, その通気量を用いた化学物質の大気中濃度の推 算が可能である.

Table 1 に, SAAS と従来の HVAS, PAS について, その 特徵を示す. SAAS は, 小型で非常に軽く, 持ち運びが容 易であるうえ, 乾電池での駆動が可能なため, 設置場所の 制限が少ない。また HVAS と比較すると安価であり，災害 に備えた数量の確保もしやすいため, 面的な調查が可能と なる.

このSAAS で得られた捕集物質を，前处理せず，加熱脱 着（TD）法により全量を測定装置に導入することで, 迅速 かつ簡易, 高感度な分析が可能になる. 測定には, 包括的 2 次元ガスクロマトグラフィ $(\mathrm{GC} \times \mathrm{GC}) /$ 高分解能飛行時 間型質量分析法（HRToFMS）を用いることにより，副生 物や反応生成物など, 事故等から直接に想定される以外の 物質も含めた網羅的かつ成分同定可能な分析が可能となる と期待される.

本報では，新たに開発した TD 法を想定した捕集材を用 いたSAASによるサンプリングと, TD 法による全量導入と GC $\times$ GC-HRToFMS を組み合わせた高感度・高分離・網羅 的分析手法を用い，大気中残留性有機污染物質の捕集特性 と適用性の評価を行った結果について報告する.SAASの 捕集材としてポリジメチルシロキサン（PDMS）を採用し， SAASによる大気中有機ハロゲン化合物の推算濃度を,

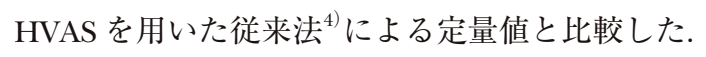

$$
2 \text { 実験 }
$$

$2 \cdot 1 \quad$ サンプリング

小型 SAAS として, 乾電池で駆動する柴田科学製 DAS -

Table 1 Comparison of characteristics for air samplers

\begin{tabular}{lccc}
\hline \multicolumn{1}{c}{ Air sampler } & SAAS $^{\text {a) }}$ & HVAS $^{\text {b) }}$ & PAS $^{\text {c) }}$ \\
\hline Portability & very easy & hard & easy \\
Large volume collection & hard & very easy & very hard \\
Sample cleanup & unnecessary & very hard & hard \\
Cost of apparatus & reasonable & expensive & reasonable \\
Flow rate & passable & exact & estimation \\
\hline
\end{tabular}

a) Semi-active air sampler, b) High volume air sampler, c) Passive air sampler. 


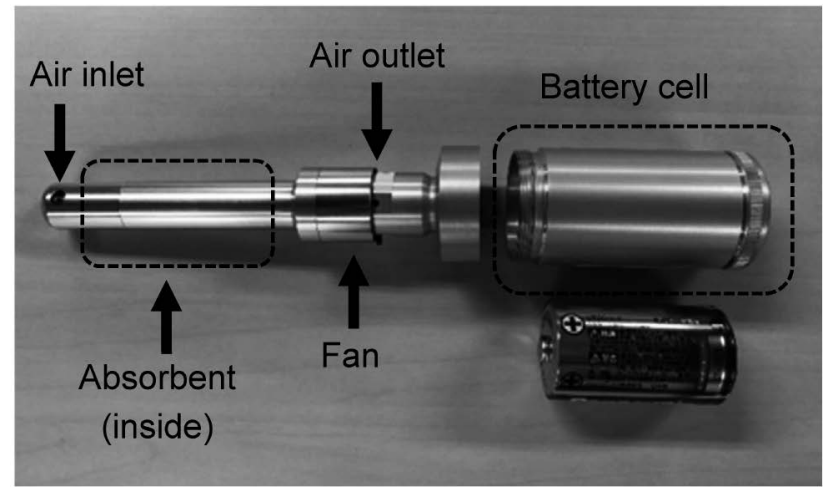

Fig. 1 Semi-active air sampler (SAAS)

100 を採用し, 通気流速の安定化, 動作状態の可視化など の改良を施した，さらに単 1 形乾電池を用いて連続 2 週間 の駆動を可能にした (DAS - 300 A). Fig. 1 に, 本研究で用 いたSAAS の写真を示す．内部には小型のファンが付いて 抢り, 平均流速 $0.486 \mathrm{~L} \mathrm{~min}^{-1}$ にてサンプリングを行える. Fig. 1 の左端が外せるようになっており, 捕集材は, そこ から内部に設置する，サンプリング後の試料は，TD 法に よる全量導入を行うことを想定し, SAASの捕集材は, 水 分の影響を受けにくく，TD による耐久性や使用実績があ る PDMS 被膜（厚さ $1 \mathrm{~mm}$ ) の小型摬找年（ゲステル製 Twister）を採用した. SAAS によるサンプリングは，2020 年 4 月 14 日から 5 月 22 日までの間に, 1 週間のサンプリ ングを 3 回実施した. SAAS は, すべての期間で 3 台並行 してサンプリングを行った. SAASのサンプリング量は, 平 均 $4.42 \mathrm{~m}^{3}$ /週であった. 本検討では, 雨風を避けるため, SAAS サンプリング時に Fig. 2 のように HVAS を利用した が，別途，災害時に使用することを想定した SAAS 用の雨 避けを検討中である.

SAAS の捕集能力を評価するため, 従来の HVAS を 1 台 用いて, SAAS と並行してサンプリングを行った. HVAS の 捕集には, 石英瀻維フィルター $(\mathrm{QFF})$, ポリウレタン フォーム (PUF), 活性炭瀻維フエルト（ACF）を使用した。 サンプリング流量は $100 \mathrm{~L} \mathrm{~min}^{-1}$ とし, SAAS と同じく 1 週 間吸引を行った. HVAS のサンプリング量は, $1008 \mathrm{~m}^{3} /$ 週 であった、サンプリングは, SAAS と HVAS ともにつくば 市にある国立環境研究所の屋上で行った。

\section{$2 \cdot 2$ 試 薬}

SAAS 試料の定量には，有機ハロゲン化合物等を含んだ 混合標準溶液（CIL 製 ES-5521）を用いた. HVAS 試料の定 量には, 同位体ラベル化した有機ハロゲン化合物混合標準 溶液（CIL 製 ES-5349）をサンプリングスパイク兼クリー ンアップスパイクとして使用した。溶媒は，すべて富士フ イルム和光純薬製の残留農薬・PCB 試験用を用いた。

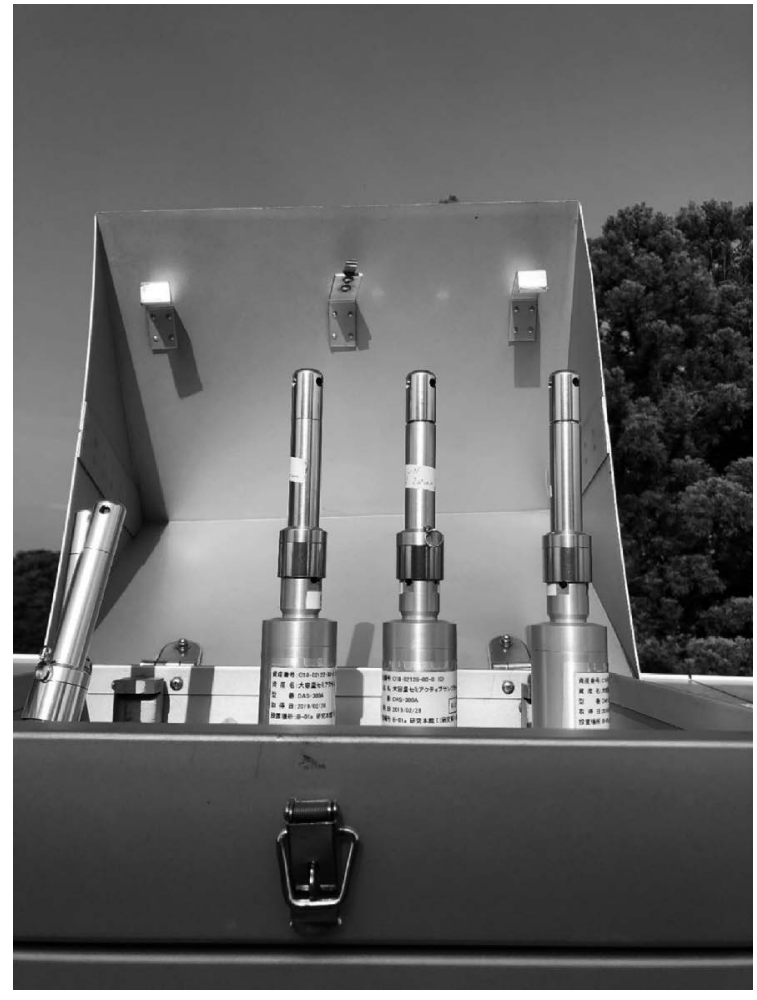

Fig. 2 SAAS Sampling

\section{$2 \cdot 3$ 試料前処理}

小型擋找子は，サンプリングを開始する前に，ゲステル

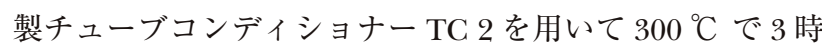
間, 窒素流量 $175 \mathrm{~mL} \mathrm{~min}^{-1}$ でエージングを行った. SAAS を用いてサンプリングを行った小型摚拌子は，そのまま TD 法にて測定を行った. HVAS は, サンプリングの直前に QFE に同位体ラベル化した有機ハロゲン化合物混合標準 溶液を添加し，捕集を開始した，HVASで捕集を行った QFF，PUF，ACFは，高速溶媒抽出装置（Dionex 製 ASE 350）を用いて抽出を行った. 抽出温度は $100{ }^{\circ} \mathrm{C}$ とし, 加 熱時間は 5 分, 静置時間は 5 分とした. HVASに扔ける各 捕集材の抽出溶媒として，それぞれ以下を使用した。 QFF: 1 回目抽出溶媒アセトン, 2 回目抽出溶媒卜ルエン, PUF: アセトン, ACF: 1 回目抽出溶媒アセトン, 1 回目抽出溶媒 トルエン。得られた抽出液は混合し, 初めにフロリジル $(10 \mathrm{~g}$; 第 1 画分 $5 \%$ ジエチルエーテル/ヘキサン $100 \mathrm{~mL}$, 第 2 画分 $20 \%$ ジエチルエーテル/ヘキサン $100 \mathrm{~mL}$ ）を用 いてクリーンアップを行い, その後, 第 1 画分をさらにシ リカゲル (5 g; $130{ }^{\circ} \mathrm{C}$ で活性化済み; 第 3 画分; ヘキサン $30 \mathrm{~mL}$, 第 4 画分 $25 \%$ ジエチルエーテル/ヘキサン 30 $\mathrm{mL}$ ）を用いてクリーンアップを実施した.

\section{$2 \cdot 4$ 分析装置と測定条件}

SAAS で捕集した試料の測定には，ZOEX 製 KT2006 GC× GC モジュレーターを内蔵したアジレント製 7890 


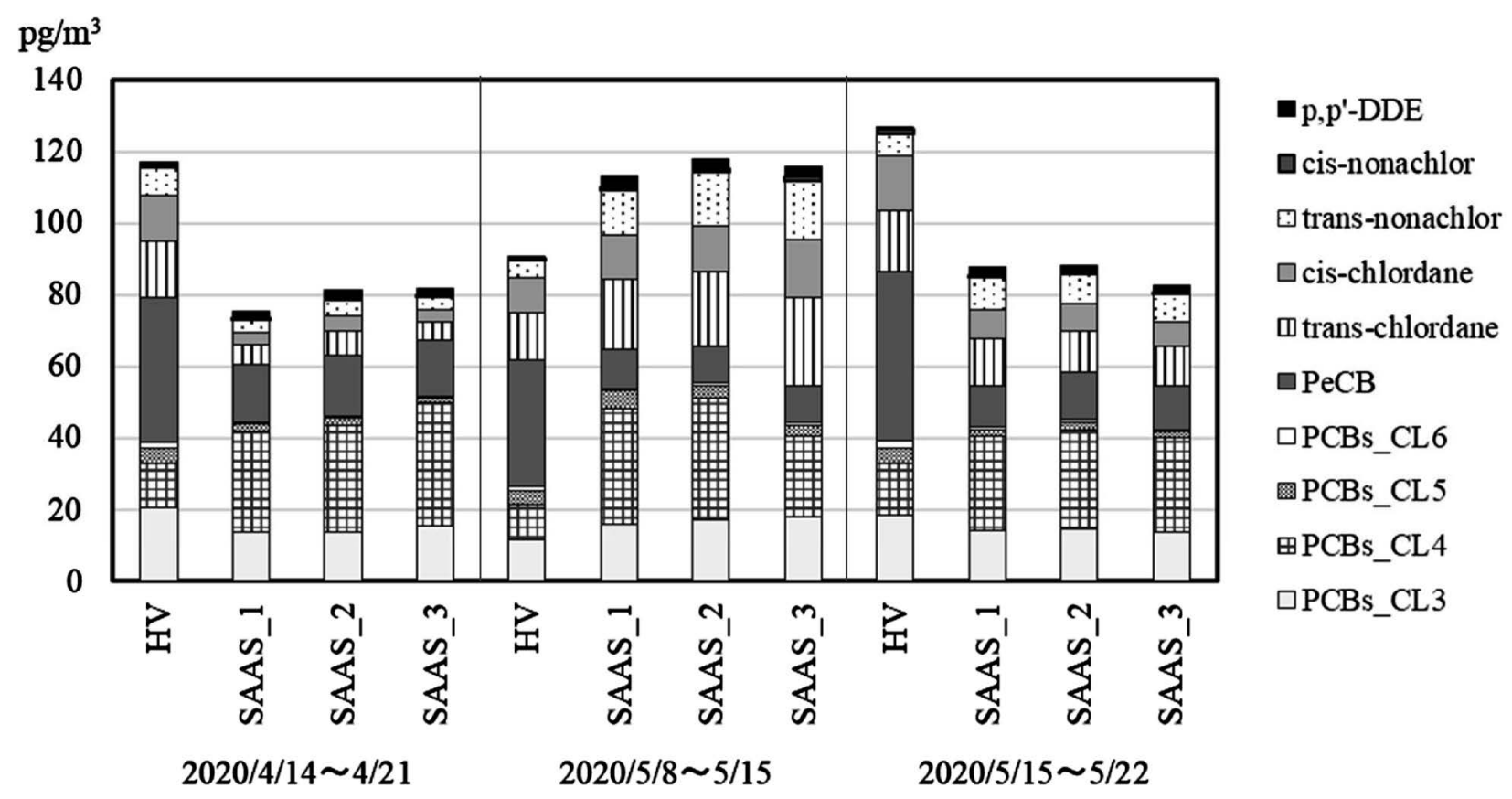

Fig. 3 Comparison of organohalogen compound concentrations obtained by SAAS and HVAS

GC-7200 B 四重極飛行時間型質量分析装置（Q-TOF）を用 いた．試料の導入は，TD装置（ゲステル製 TDU）により 行い, 溶媒抽出や前処理を省略することで成分の損失を防 いだ. TD は, $50{ }^{\circ} \mathrm{C}$ で 1 分保持したのち, $720{ }^{\circ} \mathrm{C} \mathrm{m^{-1 } て ゙}$ $280{ }^{\circ} \mathrm{C}$ まで昇温し, 10 分間保持した. $\mathrm{GC} \times \mathrm{GC}$ の 1 st カラ ムには InertCap 5MS/Sil (45 m length, 0.25 mm i.d., 0.1 $\mu \mathrm{m}$ film thickness; GL サイエンス製）を，2nd カラムには BPX-50 (0.9 m length, $0.10 \mathrm{~mm}$ i.d., $0.10 \mu \mathrm{m}$ film thickness; SGE 製) を用い, GC× GC のモジュレーションピリ オドは 6.5 秒とした. $\mathrm{GC}$ オーブンは, $50{ }^{\circ} \mathrm{C}$ で 2 分間保持 したのち, $3{ }^{\circ} \mathrm{C} \mathrm{min}^{-1} に て 350{ }^{\circ} \mathrm{C}$ まで昇温した. キャリ ヤーガスにはへリウムを用い, 流量は $1.8 \mathrm{~mL} \mathrm{~min}{ }^{-1}$ とし た. Q-TOF は, MS/MS の機能を利用せず, EI 法にてイオ ン化を行ったのち， $m / z 33 \sim 1000$ の質量範囲ですべての 精密質量スペクトルを取得した。データ取込み速度は, 25 $\mathrm{Hz}$ とした. 定量は, 絶対検量線法を用いて行った. 検量線 用の混合標準溶液は. クリーンナップ済みの石英ウールに 添加後, 小型擋拌子と同じ条件で全量を加熱脱着導入し, GC× $\times$ GC-MS にて測定を行った.

HVAS で捕集した試料は，アジレント製 6890 GC と日本 電子製 JMS - 700 MStation 高性能二重収束質量分析計を用 いて測定を行った. GC カラムには ENV- 8 MS (30 m length, $0.25 \mathrm{~mm}$ i.d. $0.25 \mu \mathrm{m}$ film thickness; 関東化学製) を用い た. GCオーブンは, $60{ }^{\circ} \mathrm{C}$ で 5 分間保持したのち, $30{ }^{\circ} \mathrm{C}$ $\min ^{-1}$ にて $200{ }^{\circ} \mathrm{C}$ まで昇温, さらに $5{ }^{\circ} \mathrm{C} \mathrm{min}{ }^{-1} に て 290{ }^{\circ} \mathrm{C}$ まで昇温した. キャリヤーガスにはへリウムを用い, 流量 は $1.0 \mathrm{~mL} \mathrm{~min}{ }^{-1}$ とした。質量分析装置の測定条件は, 環境 省のモニタリング調査マニュアル に基づいて設定し, EI
法にて測定を行った．分析は，同位体希釈法に基づき行っ た.

\section{3 結果と考察}

\section{$3 \cdot 1$ サンプリング概要}

Table 1 に, 国立環境研究所の屋上で行ったサンプリン グについて, 日程, サンプリング期間中の降水量, 気温, 湿度, 平均風速を示す. 3 回のサンプリング期間中, 湿度 や平均風速に大きな違いはなかったが, 2020 年 4 月 14 日 から 22 日，5月 15 日から 22 日の二つの期間においては, まとまった量の降水があった。

\section{$3 \cdot 2$ SAAS と HVAS の比較}

$3 \cdot 2 \cdot 1$ 有機ハロゲン化合物の濃度本研究では, 災 害発生後の污染地における吸気曝露を想定しているため, 蒸気圧がやや高めで残留しやすい化学物質として PCBs, ノナクロル, クロルダン, ペンタクロロベンゼン, $p, p^{\prime}-$ DDE を選定した。 また SAAS は，HVASのように，通過大 気中の物質を全量吸着させる手法ではなく, 吸着材表面と 接触大気の分配によって捕集される物質量が変化する手法 である，本研究では，SAAS 内を通気した空気中の物質が すべて捕集材に捕集されたと仮定して，大気濃度を算出し た.よって本報では，SAASで捕集した化合物の大気中濃 度を算出した結果は, 推算值と表記する.

Fig. 3 に, SAAS と HVAS で得られた大気中有機ハロゲン 化合物の推算值と定量值を示す。試料あたりの大気捕集量 は, HVAS で約 $1000 \mathrm{~m}^{3}$ に対して SAAS では約 $4.5 \mathrm{~m}^{3}$ と非 常に少なかったが, 一般大気中の対象化合物を検出できた 
Table 2 Sampling information at a rooftop of National Institute of Environmental Studies

\begin{tabular}{|c|c|c|c|c|c|c|c|}
\hline \multirow{2}{*}{ Sampling period } & \multirow{2}{*}{$\frac{\text { Precipitation } / \mathrm{mm}}{\text { Total }}$} & \multicolumn{3}{|c|}{ Temperature $/{ }^{\circ} \mathrm{C}$} & \multicolumn{2}{|c|}{ Humidity $/ \%$} & \multirow{2}{*}{$\begin{array}{l}\text { Average wind } \\
\text { speed } / \mathrm{ms}^{-1}\end{array}$} \\
\hline & & Average & Max & Min & Average & Min & \\
\hline $2020 / 4 / 14 \sim 4 / 21$ & 86 & 12 & 22 & 1.1 & 72 & 25 & 2.6 \\
\hline $2020 / 5 / 8 \sim 5 / 15$ & 2.0 & 19 & 28 & 6.8 & 71 & 21 & 2.5 \\
\hline $2020 / 5 / 15 \sim 5 / 22$ & 76 & 17 & 29 & 10 & 84 & 27 & 2.5 \\
\hline
\end{tabular}

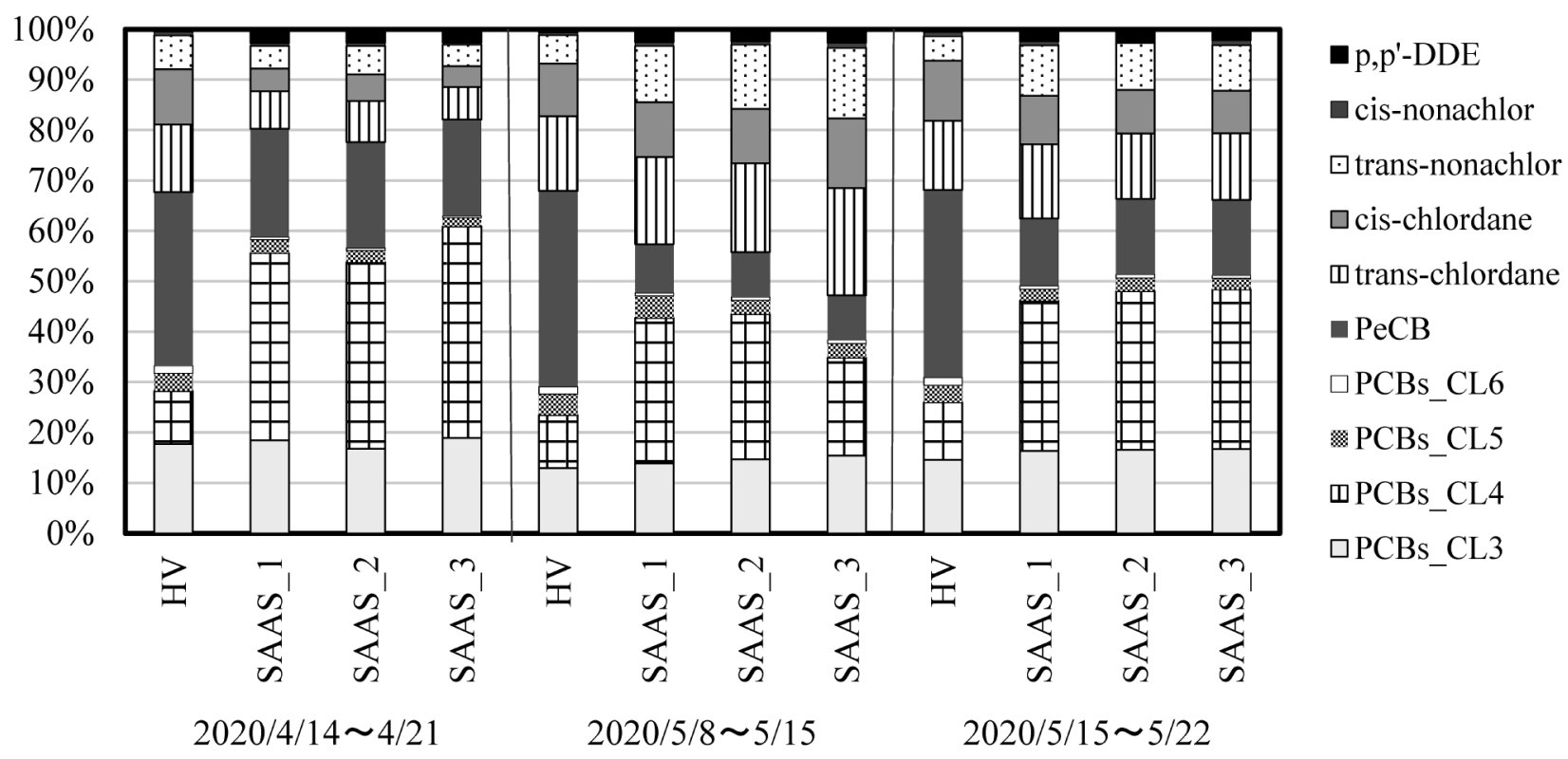

Fig. 4 Comparison of organohalogen compound composition obtained by SAAS and HVAS
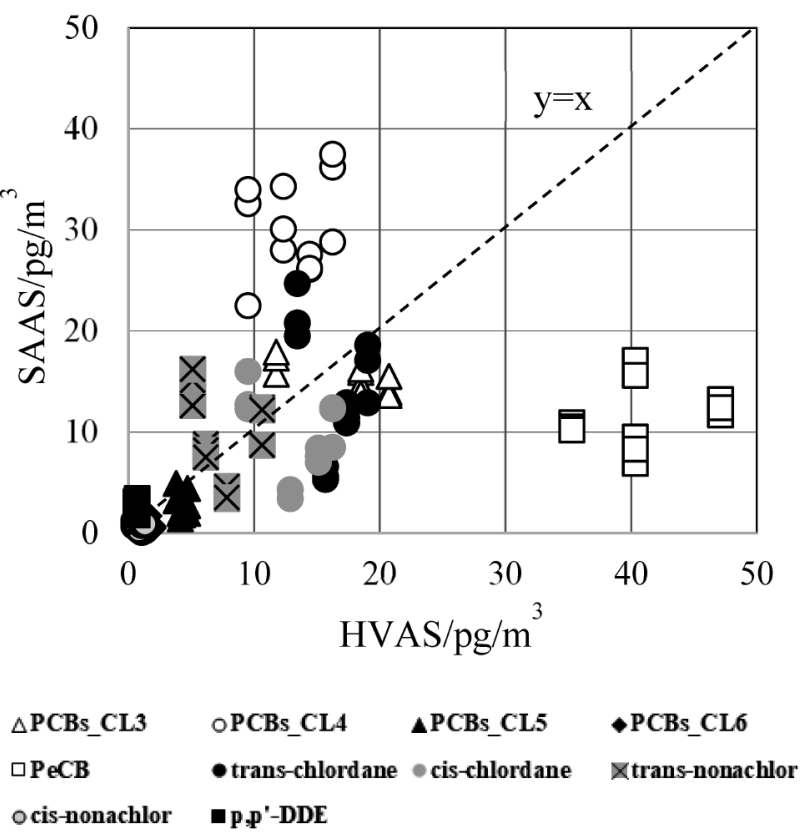

Fig. 5 Comparison of quantitative values obtained by HVAS (X axis) and SAAS (Y axis)
ことは特筆すべきである。炎などにより放出される化学 物質濃度は, これよりも高いことが想定され, 事故・災害 現場での利用が期待できる. SAAS と HVAS の結果を比較 してみると，各サンプリング期間によって差があったもの の, SAASによる推算值の合計は, HVAS による定量值の 64〜 130 \% の範囲であった。 また, 3 回のサンプリングの うち 2 回は, HVAS の定量值より SAAS の推算值が小さく なる傾向が見られた。このサンプリング期間には，まと まった降水量が観測されたことから（Table 2)，SAAS は, 湿度の影響を受けやすい可能性が示唆された。しかし, 同 一期間内の SAAS の推算值には大きなばらつきがなかった ことから, サンプリングや測定の再現性はあるものと考え られた。

$3 \cdot 2 \cdot 2$ 有機ハロゲン化合物の組成 SAAS と HVASで 捕集された対象化合物の組成を Fig. 4 に示す. Fig. 3 の結 果と同様に, SAASでは, 同一期間内で類似した組成が得 られた。 3 塩素化 PCBs（PCB_CL3），クロルデン及びノナ クロルは，捕集法によらず類似した組成比を示した。

一方で, SAASでは, 4 塩素化 PCBs (PCB_CL4) が HVAS より高い組成比を示しており, サンプリング期間を通じ て, SAAS による 4 塩素化 PCBs 推算值は HVAS の $240 \%$ 
Table 3 Correlation between quantitative values obtained by HVAS and SAAS. Vapor pressure for each compound

\begin{tabular}{lccc}
\hline & Linear regression & $R$-squared & Vapor pressure $/ \mathrm{Pa}$ at $25^{\circ} \mathrm{C}$ \\
\hline PCBs_CL3 & $\mathrm{y}=0.87 \mathrm{x}$ & 0.93 & $0.0136-0.143^{5)}$ \\
PCBs_CL4 & $\mathrm{y}=2.18 \mathrm{x}$ & 0.93 & $0.0000588-0.0054^{5)}$ \\
PCBs_CL5 & $\mathrm{y}=0.64 \mathrm{x}$ & 0.92 & $0.000304-0.0093^{5)}$ \\
PCBs_CL6 & $\mathrm{y}=0.49 \mathrm{x}$ & 0.65 & $0.0000198-0.00048^{5)}$ \\
PeCB & $\mathrm{y}=0.28 \mathrm{x}$ & 0.95 & $2.0^{6)}$ \\
trans-chlordane & $\mathrm{y}=0.85 \mathrm{x}$ & 0.75 & $0.0039^{7)}$ \\
cis-chlordane & $\mathrm{y}=0.67 \mathrm{x}$ & 0.72 & $0.0029^{7)}$ \\
trans-nonachlor & $\mathrm{y}=1.20 \mathrm{x}$ & 0.72 & $0.00039^{7)}$ \\
cis-nonachlor & $\mathrm{y}=0.75 \mathrm{x}$ & 0.72 & $0.00039^{7)}$ \\
p, $p^{\prime}$-DDE & $\mathrm{y}=3.98 \mathrm{x}$ & 0.93 & $0.00087^{8)}$ \\
\hline
\end{tabular}

(平均值 : 180 〜 $360 \%$ ）であった. また SAAS では, ペン タクロロベンゼン (PeCB) が低い組成比を示し, サンプリ ング期間を通じて SAAS によるペンタクロロベンゼン推算 值は, HVAS の $29 \%$ (平均值 : 17〜 42\%) であった. こ のことから, PDMS を捕集材としたSAAS と HVAS により， 物質捕集率に差があることが示唆された。

\section{3・2・3 SAAS 推算値と HVAS 定量値の相関 Fig. 5}

に, SAAS の推算値と HVAS の定量值の相関図, Table 3 に, 一次回帰式と各化合物の蒸気圧を示す. Table 3 において, 一次回帰式における $\mathrm{x}$ の係数が 1 よりも大きいほど, SAAS 推算值が HVAS 定量值よりも高い傾向にあることを意味す る. Fig. 5 において, PeCB は $\mathrm{x}<1$ となっており, PDMS を捕集材とした実験中 (平均気温 $16{ }^{\circ} \mathrm{C}$ ), SAAS では, HVAS と比べ蒸気圧の高い PeCB を十分に捕集できていな いものと考えられる. 今回の検討から, SAAS はノナクロ ルから PCBs 程度の蒸気圧を有する物質への適用は可能で あると推察された。しかしながら, 気温や湿度は対象とす る物質の捕集効率に大きく影響することが予想され，季節 を変えた実験による検証が不可欠である。 また, 環境条件 や対象物質に応じた捕集材の選択も重要な課題であり, 適 時・適材の検討も続ける必要がある.

$$
4 \text { 結 言 }
$$

災害・事故発生時に環境中に残留する化学物質への対策 実施と継続監視のためのモニタリング手法開発を目的とし て, 小型かつ電池で 2 週間まで駆動することが可能な SAAS （捕集材：PDMS）と TD-GC $\times$ GC-HRToFMS を組み合わせ た分析手法による大気中残留性有機污染物質の捕集特性及 び適用性評価を行った. SAAS と従来の HVAS を用いて並 行してサンプリングを行い, 大気中有機ハロゲン化合物に ついて濃度を比較した結果, 今回開発したPDMS を捕集材 としたSAAS では，ペンタクロロベンゼンなどの蒸気压が 高い化合物の捕集は難しかったものの, ノナクロルから PCBs 程度の蒸気圧を有する化合物への適用は可能である ものと推察された。今後は, 災害・事故発生時でのケース
スタディを行うことで，実用性の検証を重ねたい。また， PDMS 以外の捕集材も検討し，将来的には，複数の捕集材 の組合せにより，広範囲の物性に対応可能な体制を構築し たいと考えている.

謝辞

本研究課題は, 環境研究総合推進費 (JPMEERF18S 11714）により推進されていることを付記し，ここに謝意 を表します。セミアクティブエアサンプラーの改良に協力 いただいた鈴木義浩氏はじめ柴田科学株式会社の皆様に感 謝いたします。

$$
\left(\begin{array}{l}
\text { 令和 } 2 \text { 年 } 9 \text { 月 } 18 \text { 日, 日本分析化 } \\
\text { 学会第 } 69 \text { 年会において, 一部発表 }
\end{array}\right)
$$

\section{文献}

1) 総務省 報道資料 令和 2 年 5 月 29 日「令和元年 中の危険物に係る事故の概要」 available from $<$ https://www.fdma.go.jp/pressrelease/houdou/ items/200529_kiho_02.pdf>, (accessed 2021-4-23).

2) 環境研究総合推進費 戦略的研究開発課題 S-1：災 害・事故に起因する化学物質リスクの評価・管理手 法の体系的構築に関する研究, 中間評価, available from <https://www.erca.go.jp/suishinhi/seika/pdf/ seika_4_r02/s17-1.pdf>, (accessed 2021-3-31).

3) 橋本俊次, 高澤嘉一, 家田曜世：環境と測定技術, 48, 2 (2021).

4) 環境省 環境保健部 環境安全課：モニタリング 調査マニュアル (平成 16 年度版), 3. 大気中のPOPs モニタリング調査, p41-53.

5) D. Mackay, WY. Shiu, KC Ma : "Illustrate Chlordane vapor pressured handbook of physical-chemical properties and environmental fates for organic chemicals : Volume I", (1992), (Lewis Publishers).

6) ILO International Chemical Safety Cards database, available from <https://www.ilo.org/dyn/icsc/ showcard.display?p_version=2\&p_card_id=0531 >, (accessed 2021-3-31).

7) WT. Foreman, TF. Bidleman : Environ. Sci. Technol., 21, 869 (1987).

8) WF Spencer, MM. Cliath : J. Agri. Food. Chem., 20, 645 (1972). 


\title{
Development of a Comprehensive Monitoring Method for Environmental Persistent Organic Pollutants by Using Semi-active Air Sampling/Thermal Desorption Analysis
}

\author{
Teruyo IedA $^{* 1}$, Yoshikatsu Takazawa ${ }^{1}$ and Shunji Hashimoto ${ }^{1}$ \\ *E-mail : ieda.teruyo@nies.go.jp \\ ${ }^{1}$ Center for Environmental Standards and Measurement, Health and Environmental Risk Division, National \\ Institute for Environmental Studies, 16-2, Onogawa, Tsukuba-shi, Ibaraki 305-8506
}

(Received April 2, 2021; Accepted May 4, 2021)

\begin{abstract}
A method combined with sampling technology using a semi-active air sampler (SAAS) that uses PDMS as the collection material and analysis by TD-GC $\times$ GC-HRToFMS was developed for the purpose of implementing countermeasures against chemical substances remaining in the atmosphere, and the collection characteristics and applicability of persistent organic pollutants in the atmosphere by the developed method was evaluated. SAAS is small, light, easy to carry, and can be driven by dry batteries for 2 weeks, so there are few restrictions on the sampling location. It is also cheaper than the traditional high volume air sampler (HVAS) and has excellent versatility, such as observations at multiple points. Furthermore, unlike a passive sampler, the sampling flow rate can be calculated, so it is thought that the concentration can be estimated by validating applicable compounds. In this study, air sampling was performed at National Institute for Environmental Studies by SAAS using polydimethylsiloxane (PDMS) and by conventional HVAS. The concentrations of organohalogen compound obtained by two sampling techniques were compared. As a result, although it was difficult to collect compounds with high vapor pressure such as pentachlorobenzene with the SAAS using PDMS, it could be applied to compounds with the vapor pressure of PCBs from nonachlor. In the future, collecting agents other than PDMS will be considered, and we would like to build a system that can handle a wide range of physical properties by combining multiple collecting agents.
\end{abstract}

Keywords: semi-active air sampler; monitoring; disaster; persistent organic pollutants. 